\title{
Interactions of Bioactive Quince (Cydonia oblonga Mill.) Extract with Biomolecules
}

\author{
Paulina Strugała $^{\oplus}{ }^{1}$, Sylwia Cyboran-Mikołajczyk ${ }^{\oplus 1}$, Dorota Wyspiańska ${ }^{\oplus 2}$, \\ Anna Sokół-Łętowska $^{\oplus 2}$, Narcyz Piórecki ${ }^{\oplus 3,4}$ and Janina Gabrielska ${ }^{\oplus 1}$
}

\author{
${ }^{I}$ Department of Physics and Biophysics, Wroctaw University of Environmental and Life Sciences, C.K. \\ Norwida 25, 50-375 Wroctaw, Poland \\ ${ }^{2}$ Department of Fruit, Vegetable and Cereal Technology, Wrocław University of Environmental and \\ Life Sciences, Chetmońskiego 37/41, 51-630 Wroctaw, Poland \\ ${ }^{3}$ Arboretum and Institute of Physiography in Bolestraszyce, 37-700 Przemyśl, Poland \\ ${ }^{4}$ University of Rzeszów, Towarnickiego 3, 35-959 Rzeszów, Poland
}

(Received February 6, 2017; Revised June 2, 2017; Accepted June 15, 2017)

\begin{abstract}
The study is concerned with biological activity of quince (Q) fruit extract (Cydonia oblonga Mill.) towards the phosphatidylcholine liposome and the natural lipid-protein erythrocyte membrane, as well as will explaining the 40 way of interaction of the extract with the membrane. The results showed that Q extract protects lipids against oxidation induced by AAPH compound to a similar extent in two models of membrane. Studies with probes (Laurdan and DPH) located at different depths within the membrane lipid bilayer showed that extract caused an increase of the packing order of the polar heads of lipids and a slight decrease in mobility of the acyl chains. Such results suggest that extract molecules associate with the lipid and lipid-protein membrane and can stop the propagation of free radicals within the bilayer by modifying the membrane fluidity. Furthermore, Q extract resulted in the inhibition of the activity of enzymes (cyclooxygenase-1 and cyclooxygenase-2) probably involved in inflammatory reactions in the body. The experimental results proved that extract components can bind to the main plasma protein - human serum albumin, and the quenching mechanism was suggested as static. The obtained quince-albumin binding constants show that the extract probably can be transported from the circulatory system to reach its target organ.
\end{abstract}

Keywords: Cydonia oblonga Mill.; lipids peroxidation; erythrocyte and phosphatidylcholine membranes; human serum albumin; COX-1 and COX-2 enzymes; fluorimetric study. (C) 2017 ACG Publications. All rights reserved.

\section{Introduction}

Epidemiological studies suggest a close relation between human diet rich in substances of plant origin, phenolic compounds including, and lowered risk of the so called civilizational diseases. This has resulted in the creation of the concept of functional food and dietary supplements that contain plant preparations deemed to possess therapeutic and/or preventive action [1]. The discovery of the oxidative stress also indicates the key role of stress in inducing pathogenic processes in humans, and

*Corresponding author: E-Mail: paulina.strugala@upwr.edu.pl; Phone: +48 7132051670 Fax: +48 71320 51670. 
hence the great interest of researchers in ways of neutralizing stress. The first site that free radicals attack in the body is the cell membrane. The molecular mechanisms of the antioxidant action of phenolic compounds have not been fully explained and are still a matter of considerable discussions. Hence, the present paper is intended to explain those problems in the case of a bioactive extract of the quince fruit in action on model biological membranes.

Cydonia oblonga Mill., common name quince, subfamily Pomoideae, family Rosaceae is a perennial tree, whose fruits and leaves can be used in many ways. Health beneficial properties of quince are known from ancient times. As traditional medicine preparations from different parts of quince were used to treat cough, cystitis, constipation, cold, bronchitis, abdominal pain, diarrhea, nervousness, insomnia, disurea, against hyperglycemia and as a skin emollient [2-4]. Recent in vivo and in vitro studies have revealed that quince fruits and leaves have cell-protecting properties. Quince leaf has also been attested to possess anti-hemolytic, anti-diabetic, antilipoperoxidant and antimicrobial as well as lipid-lowering properties [5-7]. In addition quince leaves showed a concentration-dependent growth inhibitory activity towards human colon cancer cells [8]. Aqueous preparations from whole quince fruits have been reported to be effective to treat allergic disorders [9]. Finally, a lipophilic quince extract was demonstrated to exhibit skin moisturizing properties [10]. Moreover, in the work by Umar et al. [11] it is shown that Cydonia obonga (fruit and leaves) could regulate the blood lipid metabolism in using hyperlipidemic rat models while removing the oxygen free radicals and improving the antioxygenic potentials. Also, previous reports have focused either on the phytochemical composition or the bioactivity of quince [12].

The aim of the present study was to determine the biological activity of quince fruit extract to the phosphatidylcholine (PC) liposome membrane and the natural lipid-protein membrane of erythrocytes (RBC), with peroxidation induced by the AAPH compound. Extract from a natural raw material like quince fruit have a unique composition of phenols, which provide the individual value of the raw material. To investigate the interaction between the extract and the membranes, biophysical studies were undertaken using fluorescent probes that become imbedded in different areas of the bilayer. In addition, we investigated the anti-inflammatory properties of quince extract in inhibiting the cyclooxygenases 1 and 2 - the enzymes that participate in inflammatory processes, and the extract's ability to bind to the main transport protein of blood - human albumin. Such comprehensive studies on the biological activity of quince extract and the mechanism of protecting the membranes against oxidation have not yet been presented.

\section{Materials and Methods}

\subsection{Reagents and Chemicals}

N,N,N',N'-tetramethyl-p-phenylenediamine (TMPD, $\geq 97.0 \%$ ), arachidonic acid from porcine liver $(\geq 99.0 \%)$, cyclooxygenase 1 from sheep, cyclooxygenase 2 human recombinant, indomethacin ( $\geq 99.0 \%$ ), 2,2'-azobis (2-amidinopropane) dihydrochloride (AAPH, 97\%), L(+) ascorbic acid (AA) and human serum albumin (HSA) (lyophilized powder, essentially fatty acid free) were purchased from Sigma-Aldrich (Poznań, Poland). Egg yolk phosphatidylcholine (PC) was obtained from Lipid Products, UK. The probes DPH, DPH-PA, and Laurdan were purchased from Molecular Probes (Eugene, Oregon). Tris (hydroxymethyl) aminomethane (Tris:HCl) were obtained from "Chempur" Piekary Śląskie.

\subsection{Plant Material}

The raw material for the study was quince (Cydonia oblonga Mill.). The fruit of quince was collected in the Arboretum and Institute of Physiography in Bolestraszyce near Przemyśl, Poland. The plant materials were authenticated by Prof. Jakub Dolatowski (Arboretum and Institute of Physiography in Bolestraszyce), and the adequate voucher specimens BDPA 006747 has been deposited at the Herbariums of Arboretum and Institute of Physiography in Bolestraszyce. 
Fruits were harvested in October 2012 , and immediately frozen at $-20^{\circ} \mathrm{C}$. It was frozen and then freeze-dried (ChRIST ALPhA 1-4 LSC), and just before extraction it was disintegrated with an analytical mill (A11 basic of IKA-Werke, Germany). The process of obtaining the Q extract was described in with small modifications by Strugała and Gabrielska [13]. Fruit extract were obtained in the following way: $50 \mathrm{~g}$ of fruit lyophilizate was all covered in $200 \mathrm{~mL}$ of $70 \%$ water-ethanol solution, sonicated $\left(20 \mathrm{kHz}\right.$, Sonic, Italia) for $15 \mathrm{~min}$ in temperature $30^{\circ} \mathrm{C}$, and the alcoholic extract drained. The extraction process by sonication was repeated 2 more times. The extract thus obtained was spun for 15 min in a centrifuge $(2500 \mathrm{rev} / \mathrm{min})$ at room temperature and then the ethanol was evaporated to dry weight with a rotary evaporator (IKA RV 05B, Germany) for approx. $50 \mathrm{~min}$. Obtained extract was dissolved in distilled water and passed through a column $(70 \mathrm{~cm} \times 7.5 \mathrm{~cm})$ filled with Amberlite ${ }^{\circledR}$ resin (XAD4). The column was washed with distilled water (about $2600 \mathrm{~mL}$ ) until the wash-out of total sugars (the concentration of sugars in the extraction, measured with a Pocket PAL-1 refractometer, came to zero). Phenolic compounds were obtained after washing the column with $70 \%$ ethanol (about $1300 \mathrm{~mL}$ ). The collected fraction was evaporated in a vacuum evaporator for about an hour until dry mass. The extract thus obtained was stored at room temperature without light.

\subsection{Preparation of Erythrocyte Membranes}

Erythrocyte membranes were obtained from fresh heparinized pig blood according to the method of Dodge et al. [14]. The content of erythrocyte membranes in the samples was determined on the basis of protein concentration, which was assayed using the Bradford method [15] and it was 100 $\mu \mathrm{g} / \mathrm{mL}$. The choice of pig erythrocytes was prompted by the fact that this cell's percentage share of lipids is closest to that of the human erythrocyte. Fresh blood was taken each time to a physiological solution of sodium chloride with heparin added. In the study the erythrocyte membranes was selected as a model the cell membrane on the grounds that the presence e.g. of drugs or biologically active substances in peripheral blood makes that the substances interact with blood components, in particular with of the serum protein (including albumin) and in the first contact with the erythrocytes with their cell membrane.

\subsection{High-performance Liquid Chromatography/Mass Spectrometry (HPLC-MS/MS) methods}

Phenolic compounds were identified by the method described by Kucharska et al. [16] using the Acquity Ultra-Performance Liquid Chromatography (UPLC) system coupled with a quadruple time-of-flight (Q-TOF) MS instrument (Waters Corp., Milford, MA, USA) with an electrospray ionization (ESI) source. Separation was achieved on an Acquity BEH C18 column $(100 \mathrm{~mm} \times 2.1 \mathrm{~mm}$ i.d., $1.7 \mu \mathrm{m}$; Waters). Detection wavelengths were set to $280,320,360 \mathrm{~nm}$. The mobile phase was a mixture of $4.5 \%$ formic acid (A) and acetonitrile (B). The gradient program was as follows: initial conditions $-99 \%$ (A), $12 \mathrm{~min}-75 \%$ (A), $12.5 \mathrm{~min}-100 \%$ (B), $13.5 \mathrm{~min}-99 \%$ (A). The flow rate was $0.45 \mathrm{~mL} / \mathrm{min}$ and the injection volume was $5 \mu \mathrm{L}$. The column was operated at $30^{\circ} \mathrm{C}$. UV-VIS absorption spectra were recorded on-line during HPLC analysis, and the spectral measurements were made in the wavelength range of 200-600 nm, in steps of $2 \mathrm{~nm}$. The major operating parameters for the Q-TOF MS were set as follows: capillary voltage $2.0 \mathrm{kV}$, cone voltage $40 \mathrm{~V}$, cone gas flow $11 \mathrm{~L} / \mathrm{h}$, collision energy $28-30 \mathrm{eV}$, source temperature $100^{\circ} \mathrm{C}$, desolvation temperature $250^{\circ} \mathrm{C}$, collision gas argon, desolvation gas (nitrogen) flow rate $600 \mathrm{~L} / \mathrm{h}$, data acquisition range $\mathrm{m} / \mathrm{z}, 100-1000 \mathrm{Da}$, ionization mode, negative and positive. The data were collected with Mass-Lynx V 4.1 software.

Quantification of phenolic compounds was performed by the method described by SokólŁętowska et al. [17] using the Dionex HPLC (Sunnyvale, CA, USA) system equipped with a diode array detector (model Ultimate 3000), a quaternary pump (LPG-3400A), an auto-sampler (EWPS3000SI), and a thermostated column compartment (TCC-3000SD), controlled by Chromeleon v.6.8 software. Separation was performed on a Cadenza C5-C18 $(75.0 \times 4.6 \mathrm{~mm}, 5 \mu \mathrm{m})$ column (Imtakt, Japan) with a guard column. Oven temperature was set to $30^{\circ} \mathrm{C}$. The mobile phase was composed of solvent A (4.5\% formic acid, v/v) and solvent B (acetonitrile). The applied elution conditions were: 0 $1 \min 5 \%$ B, $20 \min 25 \%$ B, $21 \min 100 \%$ B, $26 \min 100 \%$ B, $27 \min 5 \%$ B. The flow rate was 
$1.0 \mathrm{~mL} / \mathrm{min}$, and the injection volume was $20 \mu \mathrm{L}$. Flavonols were detected at $360 \mathrm{~nm}$, phenolic acids at $320 \mathrm{~nm}$, and flavanols at $280 \mathrm{~nm}$. Flavonols were quantified as quercetin 3-O-glucoside, phenolic acids as 5'-caffeoylquinic acid, flavanols as (-)-epicatechin. The results were calculated as $\mathrm{mg}$ of compound in $1 \mathrm{~g}$ dry mass of extract (mg/g of d.m.) All determinations were performed in duplicate. The detailed information of the HPLC-MS/MS method with original chromatograms are given in supporting information part (are shown in S1-S19).

\subsection{Antioxidant Activity - Fluorometric Method}

Antioxidant activities of $\mathrm{Q}$ and AA were determined using the fluorimetric method $[18,19]$. The studies were carried out on RBC membranes and PC liposomes in phosphate buffer (pH 7.4) at $0.1 \mathrm{mg} / \mathrm{mL}$ that contained the fluorescent probe DPH-PA $(1 \mu \mathrm{M})$. Use was made of the relationship between DPH-PA fluorescence intensity and concentration of free radicals. The probe's fluorescence decreased with its rising oxidation caused by free radicals, supplied by AAPH at a final concentration of $1 \mathrm{M}$ at $37{ }^{\circ} \mathrm{C}$. As a measure of the degree of erythrocyte and lipid membranes oxidation was assumed the value of relative intensity of DPH-PA fluorescence [20]. It was calculated as a ratio of fluorescence intensity after $30 \mathrm{~min}$ of oxidation in the presence of antioxidants to the initial value of the intensity. The concentrations of antioxidants were changed in the range $4-10 \mu \mathrm{g} / \mathrm{mL}$ for $\mathrm{Q}$ and $12-$ $35 \mu \mathrm{g} / \mathrm{mL}$ for AA. The measurements were conducted with a fluorimeter (Cary Eclipse, Varian) in five independent replicates $(n=5)$.

\subsection{Packing Order and Fluidity of Membrane}

The effects of extracts on the packing order of the hydrophilic phase of PC and RBC membrane were examined using the Laurdan probe, while on the basis of changes in fluorescence anisotropy of the probe DPH the effect of extract on fluidity of the hydrophobic part of the membrane was examined [18]. The effects of Q extracts on the packing order of the hydrophilic phase of PC and RBC membrane were examined using the Laurdan probe, while on the basis of changes in fluorescence anisotropy of the probe DPH the effect of extract on fluidity of the hydrophobic part of the membrane was examined. The prepared PC liposomes and RBC membranes were suspended in a phosphate buffer ( $\mathrm{pH} 7.4$ ), and incubated for $0.5 \mathrm{~h}$ in the dark in the presence of a probe. The sample included: PC or RBC liposomes $(0.1 \mathrm{mg} / \mathrm{mL})$, fluorescent probe $(1 \mu \mathrm{M})$ and $\mathrm{Q}$ extract at a concentration varying within the range $4-20 \mu \mathrm{g} / \mathrm{mL}$. Measurements were carried out at room temperature (approx. $20{ }^{\circ} \mathrm{C}$ ). The excitation and emission wavelengths for DPH were as follows: $\lambda_{\mathrm{ex}}=360 \mathrm{~nm}$ and $\lambda_{\mathrm{em}}=425 \mathrm{~nm}$. The excitation wavelength for Laurdan was $360 \mathrm{~nm}$, and the emitted fluorescence was recorded at two wavelengths, 440 and $490 \mathrm{~nm}$. The experiments were conducted with a fluorimeter (Cary Eclipse, Varian) in six independent replicates ( $\mathrm{n}=6)$.

\subsection{Fluorescence Quenching of Human Serum Albumin}

Analysis of the potential interaction of Q and AA with human serum albumin (HSA) was performed according to the work by Trnková et al. [21] and Strugała et al. [18] with minor modifications. All quenching experiments were performed at 295, 300, 305 and $310 \mathrm{~K}$ temperature for HSA in a phosphate buffer solution of $\mathrm{pH} 7.4$ and final concentration $1.5 \times 10^{-5} \mathrm{M}$. The excitation wavelength was set at $280 \mathrm{~nm}$ (excitation of the Trp and Tyr), and the emission spectra were read at $285-460 \mathrm{~nm}$. The excitation and emission slits were both set to $5 \mathrm{~nm}$. Our method consisted in tracking the quenching of natural HSA fluorescence caused by Q and AA added successively. The final concentrations varied in the range $2.5-75 \mu \mathrm{g} / \mathrm{mL}$ for $\mathrm{Q}$ and $5-100 \mu \mathrm{g} / \mathrm{mL}$ for AA. The experiment were performed on a fluorimeter (Cary Eclipse, Varian) equipped with $1.0 \mathrm{~cm}$ quartz cells and a thermostat bath in three independent replicates $(n=3)$. 


\subsection{Cyclooxygenase Activity}

The anti-inflammatory activity of the Q extract, established on the basis of a modified method given in the work by Jang and Pezzuto [22] was assayed by a spectrophotometric measurement of inhibition of activity of the cyclooxygenase COX-1 and COX-2. The experiment is described in detail by Strugała et al. [23]. The experiment was performed in five independent replicates $(n=5)$.

\subsection{Statistical Analysis}

Data are shown as mean values \pm standard deviation (SD). The results were analyzed by oneway ANOVA followed by Duncan test. P values $<0.05$ were considered statistically significant. The program Statistica 12.0 was used for all statistical calculations.

\section{Results and Discussion}

\subsection{Phenolic Content by HPLC-MS/MS Method}

By the HPLC-MS/MS chromatographic method was performed quantitative and qualitative analysis of the components present in the $Q$ extract and the results (expressed in $\mathrm{mg} / \mathrm{g} \mathrm{d.m}$ ) are presented in Table 1. The developed and validated HPLC method was assessed by different validation parameters. According to results, the linearity from validation parameters was found to be consistent with correlation coefficients between 0.9999 and 0.9995 . The detection and quantification limits of each phenolic compound were remarked in S1 (Supporting information).

Phenolic compounds contained in the extract belong to 3 groups of substances: phenolic acids (ca. 84\%), flavonols - glycoside and rutinoside of quercetin, (ca. 8\%) and flavon-3ols - catechins and procyanidins (ca. 8\%). These tree groups were also identified by other researchers from extracts of various parts of fruits: (pulp, peel, seed), [24,5,12]. In total, 13 phenolic compounds were found and identified. The most numerous of the three groups were phenolic acids, were chlorogenic acid and neochlorogenic dominated, their percent shares being 37.4 and $33.5 \%$, respectively.

The structural characteristics of Cydonia oblonga Mill. compounds were based on retention times, UV-visible spectra, mass spectra, and ion fragmentation. The results were compared to available authentic standards and by comparison with literature data [25-27]. In the quince extract phenolic acids were identified (chlorogenic acid and its isomers - neochlorogenic and cryptochlorogenic acids, derivatives of caffeoylquonic acid, p-coumaric acid and dicaffeoylquinic acid). Compounds at $t_{R} 2.10 \mathrm{~min}$, and $3.19 \mathrm{~min}$ had comparable retention times and spectrum at $\lambda_{\max }$ at $325 \mathrm{~nm}$ to authentic standards of neochlorogenic and chlorogenic acid respectively. They exhibited a pseudomolecular ion at $\mathrm{m} / \mathrm{z}$ 353.1. After fragmentation, ions with characteristic for quinic acid $(\mathrm{m} / \mathrm{z}$ at 191.1) caffeic acid $(\mathrm{m} / \mathrm{z}$ at 179.0 and 135.0) were obtained. Similar pattern of fragmentation was observed for compound at $3.46 \mathrm{~min}$, so this compound was tentatively identified as cryptochlorogenic acid. Compound at $t_{R} 7.53$ was identified as dicaffeoylquinic acid. Fragmentation of the ion with $\mathrm{m} / \mathrm{z}$ 515,1 created ions at $\mathrm{m} / \mathrm{z} 353.1$, at $\mathrm{m} / \mathrm{z}$ 191.1, at $\mathrm{m} / \mathrm{z}$ 179.0. Ion at $\mathrm{m} / \mathrm{z} 337.1\left(t_{\mathrm{R}} 2.88 \mathrm{~min}\right)$ was identified as derivative of quinic acid and $p$-coumaric acid because after fragmentation specific molecular ions at $\mathrm{m} / \mathrm{z}, 191.1,163.0$ and 119.1 were reveald. In quince extract derivative of quinic and $p$-coumaric acids with ions at $\mathrm{m} / z 337.1$ and $\mathrm{m} / \mathrm{z} 191.1$ at $t_{\mathrm{R}} 4.55 \mathrm{~min}$ was also identified. Derivatives of quercetin: quercetin 3-O-rutinoside, quercetin 3-O-glucoside (isoquercitrin) were identified. Fragmentation pattern shows that residues of glucose and rhamnose were attached to aglycone. Pseudomolecular ion at $\mathrm{m} / z 609.1\left(t_{\mathrm{R}} 6.56 \mathrm{~min}\right)$ and $463.1\left(t_{\mathrm{R}} 6.67 \mathrm{~min}\right)$ created ions characteristic at $\mathrm{m} / \mathrm{z} 301.1$ for quercetin aglycone from which glucose-rhamnose (308 Da) or glucose (162 Da) moiety were detached.

All flavan-3 ols showed characteristic UV spectra at $\lambda \max =280 \mathrm{~nm}$ and the characteristic ions at $m / z$ corresponding to dimer $\left(m / z 577.1, t_{R} 3.41\right)$, and monomer $\left(m / z 289.1, t_{R} 4.03\right)$. An authentic standard of $(+)$ catechin and procyanidin $B 2$ have a comparable spectrum and $t_{R}$. Fragmentation of compound with $\mathrm{m} / \mathrm{z}$ at 865.2 and $\mathrm{t}_{\mathrm{R}} 4.39 \mathrm{~min}$ gave ions with $\mathrm{m} / \mathrm{z} 577.1$ and 289.1, 
characteristic for procyanidin dimer and monomer respectively. This compound was identified as procyanidin $\mathrm{C} 1$ [27].

Table 1. Content, $\mathrm{mg} / \mathrm{g}$ d.m., and characterization of phenolic compounds of the preparation of Cydonia oblonga Mill. (quince).

\begin{tabular}{clcccl}
\hline $\begin{array}{c}\text { Peak } \\
\text { No }\end{array}$ & Phenolic compounds & $\begin{array}{c}\text { Content } \\
{[\mathbf{m g} / \mathbf{g}]}\end{array}$ & $\begin{array}{c}\mathbf{R t} \\
{[\mathbf{m i n}]}\end{array}$ & $\begin{array}{c}{[\mathbf{M}-\mathbf{H}]-\mathbf{m}} \\
{[\mathbf{m} / \mathbf{z}]}\end{array}$ & $\begin{array}{l}\text { MS/MS } \\
\text { fragments } \\
{[\mathbf{m} / \mathbf{z}]}\end{array}$ \\
\hline & & & & & \\
1 & neochlorogenic acid & 50.53 & 2.10 & 353.1 & 191.1 \\
2 & p-coumaroylquinic acid & 7.64 & 2.88 & 337.1 & 163.0 \\
3 & chlorogenic acid & 56.39 & 3.19 & 353.1 & 191.1 \\
4 & cryptochlorogenic acid & 1.97 & 3.46 & 353.1 & 191.1 \\
5 & caffeoylquinic acid derivatives & 1.11 & 4.58 & 353.1 & 191.1 \\
6 & p-coumaric acid derivative & 4.55 & 4.46 & 337.1 & 191.1 \\
7 & caffeoylquinic acid derivatives & 2.63 & 7.54 & 353.1 & 191.1 \\
8 & dicaffeoylquinic acid & 1.38 & 7.53 & 515.1 & $353.1 / 191.1$ \\
9 & quercetin - 3- $O$-rutinoside & 9.02 & 6.56 & 609.1 & 301.0 \\
10 & quercetin - 3- $O$-glucoside & 3.05 & 6.67 & 463.1 & 300.0 \\
11 & catechin & 3.97 & 4.03 & 289.1 & - \\
12 & procyanidin B2 & 1.66 & 3.41 & 577.1 & 289.1 \\
13 & procyanidin C1 & 6.75 & 4.39 & 865.2 & 289.1 \\
& & & & & \\
\hline
\end{tabular}

\subsection{Antioxidant Activity}

The antioxidant activity of $\mathrm{Q}$ extract was expressed in parameter $\mathrm{IC}_{50}(\mu \mathrm{g} / \mathrm{mL})$. From comparison of the $\mathrm{IC}_{50}$ values (Table 2 ) it follows that the commonly used food antioxidant - ascorbic acid shows weaker antioxidant activity than quince extract, from about 2.8 -fold in the case of PC membrane to ca. 2.0-fold for RBC membrane. Such a high activity may result from favorable molecular structure of the Q components, which include phenolic acid but also flavonols and flavan-3ols [28]. Our previous results [18] showed that the main component of the extract of quince chlorogenic acid has about 3.3 and 7.7 (for PC membrane and RBC, respectively) times greater activity than quince extract (Table 2). It can be assumed that the antioxidant activity of the extract is related to the high content of chlorogenic acid, which has a high antioxidant capacity.

To sum up, these results showed high activity of Q to prevent the lipid peroxidation induced by the hydrophilic radical generator AAPH. There are hypotheses possible that could explain this antioxidant effect. Quince extract molecules in the water phase could have stopped the penetration to the membrane of free radicals in redox reaction before they have reached the lipids. The extract molecules probably could also associate with the lipid membrane and decrease the propagation of free radicals within the bilayer either, by modifying the membrane fluidity and by scavenging the peroxyl radicals. 
Table 2. Antioxidant, antiradical and anti-inflammatory $\left(\mathrm{IC}_{50}\right)[\mu \mathrm{g} / \mathrm{mL}]$ parameters for Cydonia oblonga Mill. L(+)-ascorbic acid and indomethacin. Membrane oxidation was induced by AAPH compounds.

\begin{tabular}{ccccc}
\hline $\begin{array}{c}\text { Inducer/ } \\
\text { Mebrane/ } \\
\text { COX }\end{array}$ & $\begin{array}{c}\text { Quince } \\
{[\boldsymbol{\mu g} / \mathbf{m L}]}\end{array}$ & $\begin{array}{c}\mathbf{L}(+) \text { ascorbic acid } \\
{[\boldsymbol{\mu g} / \mathbf{m L}]}\end{array}$ & $\begin{array}{c}\text { Indomethacin } \\
{[\boldsymbol{\mu g} / \mathbf{m L}]}\end{array}$ & $\begin{array}{c}\text { Chlorogenic acid } \\
{[\boldsymbol{\mu g} / \mathbf{m L}]}\end{array}$ \\
\hline $\begin{array}{c}\text { AAPH } \\
\text { PC }\end{array}$ & $8.09 \pm 0.68$ & $22.80 \pm 2.19^{\mathrm{a}}$ & - & $2.45 \pm 0.28^{\mathrm{a}}$ \\
RBC & $6.90 \pm 0.43$ & $20.10 \pm 1.15^{\mathrm{b}}$ & - & $0.90 \pm 0.08^{\mathrm{b}}$ \\
COX-1 & $196.40 \pm 8.66$ & - & $9.15 \pm 0.23$ & - \\
COX-2 & $103.95 \pm 6.10$ & - & $7.60 \pm 0.68$ & - \\
\hline
\end{tabular}

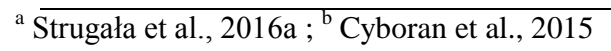
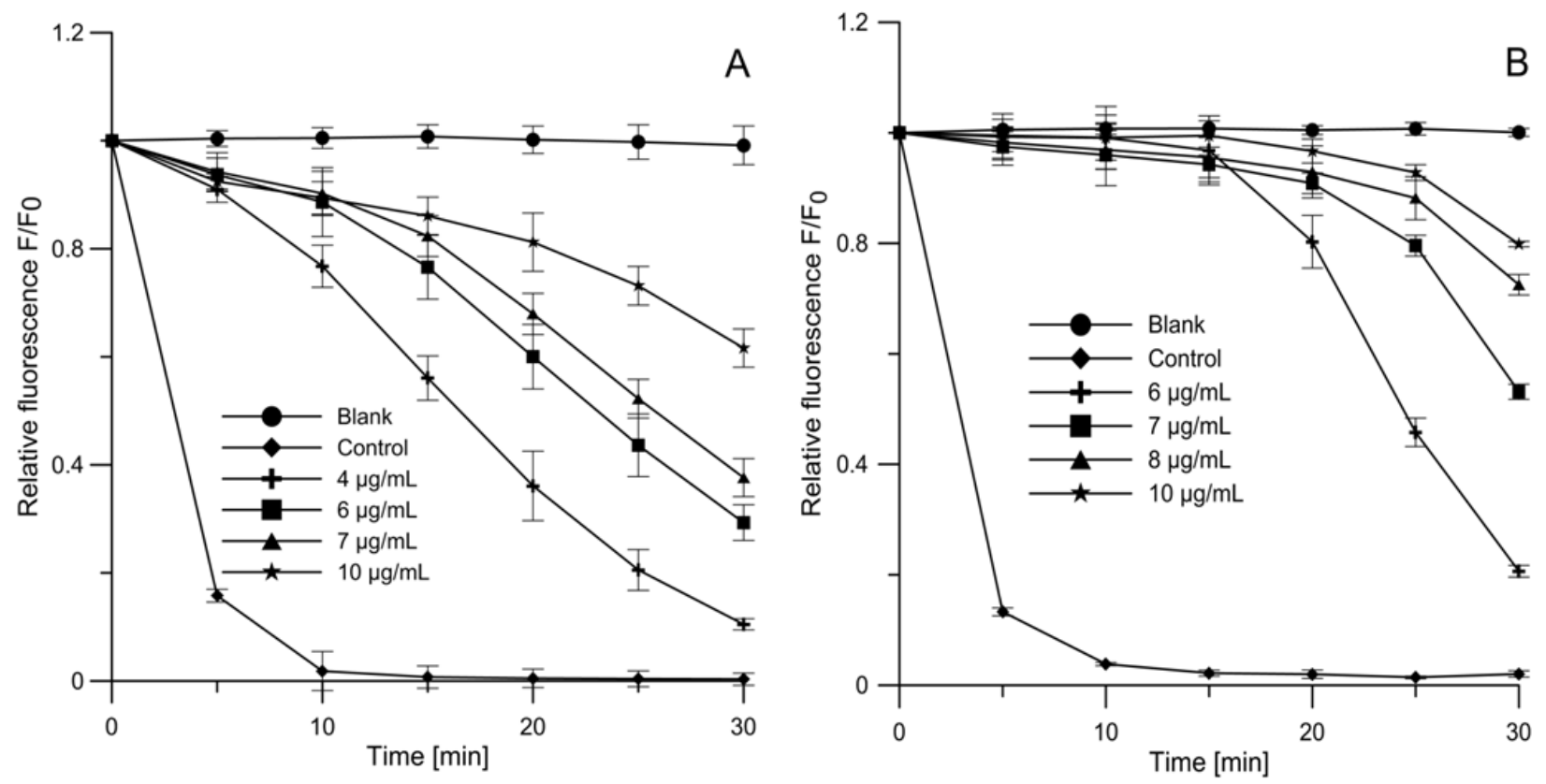

Figure 1. Relative fluorescence intensity of DPH-PA probe as a function of oxidation time. (A) liposomes PC and (B) RBC ghosts for AAPH radicals in the presence of quince extract at chosen concentrations. The relative change in fluorescence intensity $\mathrm{F} / \mathrm{F}_{0}$ is a measure of the degree of lipid peroxidation $\left(\mathrm{F}_{0}\right.$-fluorescence anisotropy in control-without quince extract, $\mathrm{F}$-fluorescence anisotropy in samples).

\subsection{Packing Order and Fluidity of Membrane}

Authors of the present work have analyzed the effect of the extract on the biophysical properties of membranes, which has not yet been reported so far. The results of studies on modification of PC and RBC membranes structure induced by Q extract, are presented in Figure 2. The chromophore Laurdan probe incorporates in the hydrophilic region of the membrane at the level of glycerol within the lipid molecule. The results indicate (Figure 2A) that Q extract in the range 4-20 $\mu \mathrm{g} / \mathrm{mL}$ caused a statistically significant $(\mathrm{P}<0.05)$, concentration-dependent increase in GP (negative values) of the single-component PC membrane in the range 10-54\% approximately. In the case of the multi-component RBC membrane there was no statistically significant change in GP (positive values) at lower concentrations of $\mathrm{Q}$ extract $(4-8 \mu \mathrm{g} / \mathrm{mL})$, while in the range $12-20 \mu \mathrm{g} / \mathrm{mL}$ it caused an increase in GP of less than 6\%, relative to control (Figure 2A). In lipid membranes the Laurdan probe is sensitive to the amount of water molecules present within the bilayer. If the lipids are ordered, water molecules will have less access to the probes embedded in the membrane, thus resulting in a high 
value of GP [29]. The results we obtained indicate that Q extract causes increased packing order of the lipid heads at the membrane interphases.

The results of measurements shown in Figure 2B proved that quince extract increased fluorescence anisotropy of the hydrophobic probe in the case of PC membrane (approx. 17\% change at $20 \mu \mathrm{g} / \mathrm{mL},(\mathrm{P}<0.05)$, relative to control). In the case of RBC membrane one can note a slight decrease in anisotropy, not exceeding $7 \%$ (statistically significant change at higher concentrations of $\mathrm{Q}$ in the range $12-20 \mu \mathrm{g} / \mathrm{mL}$ ). A change in anisotropy of a probe located in the hydrophobic part of membrane induced by a penetrating substance leads to changes in micro-fluidity of the membrane and in the dynamics of acyl chains. The increase in anisotropy of the probes indicates stiffening, while decrease in anisotropy signifies increased fluidity of the molecules or their segments in that lipid area [30].

The practical absence or a slight effect of the extract on the erythrocyte membrane is, among other things, the result of the varied structure of that membrane compared with the PC membrane. PC liposomes are formed of phospholipids of same structure of their polar heads and acyl chains that differ in length and degree of unsaturation of bonds, which results in high mobility and thus low packing order. In the case of erythrocyte membrane, due to the presence of sphingomyelin, cholesterol or possibly cytoskeleton proteins, a more order structure occurs as opposed to the liquid-disordered structures of the PC liposomes [31].

Hence the obtained effect of Q extract on the packing order of the polar heads of lipids was greater for PC liposomes than erythrocyte membranes. Our research has shown that quince extract can interact with membrane phospholipids (with polar head groups of lipids), which may result in accumulation of the extract molecules on the membrane surface. This improves membrane integrity and may constitute a barrier to the harmful molecules excessing the hydrophobic region of the bilayer [32].
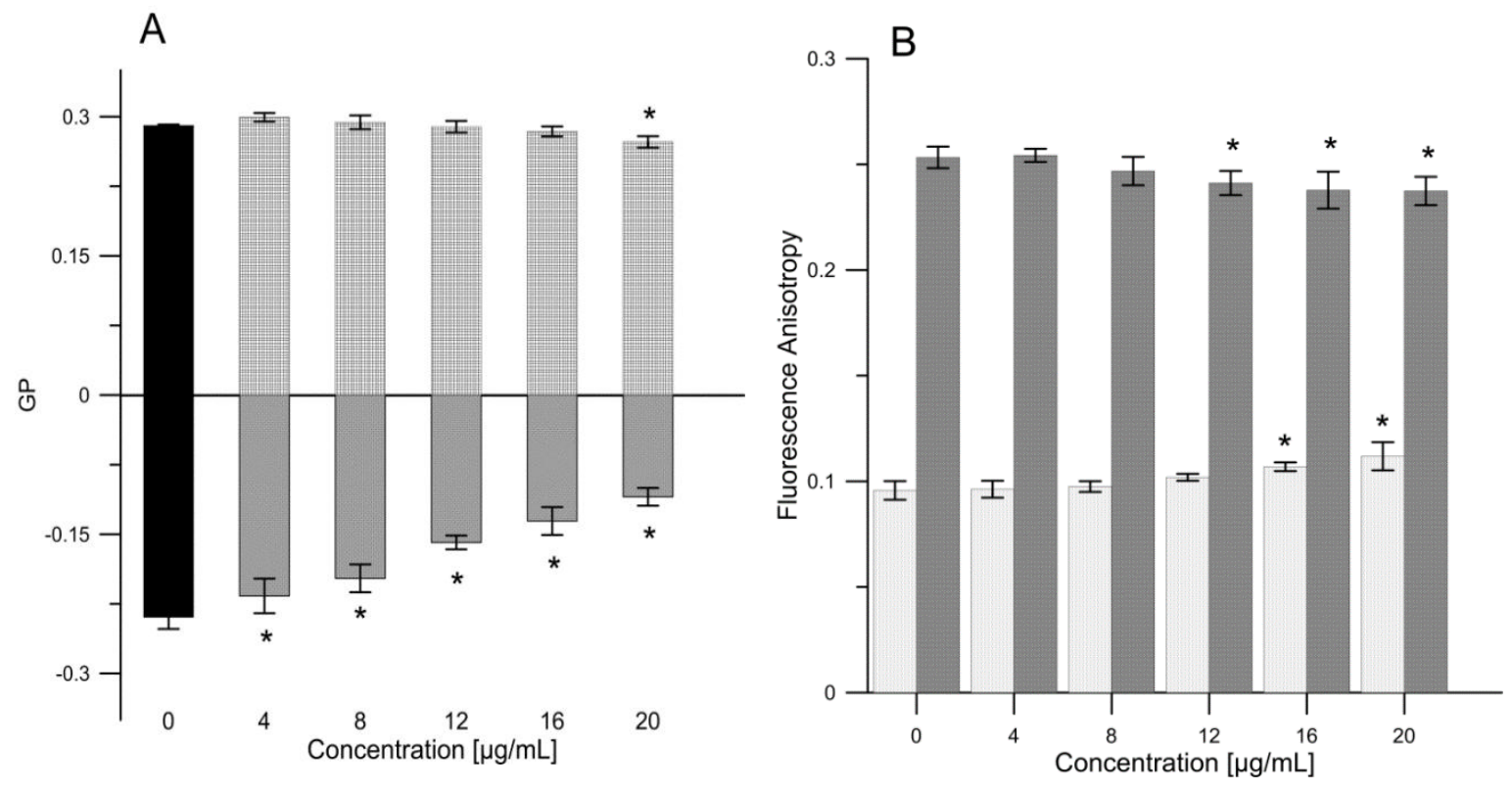

Figure 2. (A) Generalized polarization (GP) of Laurdan probe as a function of Cydonia oblonga Mill. (Q) concentration (positive values for RBC, negative for PC), (B) DPH-probe fluorescence anisotropy as a function of $\mathrm{Q}$ concentration. PC - phosphatidylcholine liposomes, RBC - erythrocyte membrane (ghosts). Values are means \pm SEM, $n=5$. Means labeled with $(*)$ are significantly $(P<0.05)$ different from control.

\subsection{Fluorescence Quenching Mechanism and Determination of Binding Parameters}

The fluorescence spectra of HSA in the absence and presence of different amounts of Q (2.5$75 \mu \mathrm{g} / \mathrm{mL})$ and AA $(5-100 \mu \mathrm{g} / \mathrm{mL})$ were recorded. The effect of Q and AA on the HSA fluorescence 
intensity is presented in Figure 3. As the data show, the fluorescence intensity of HSA decreased regularly with increasing $\mathrm{Q}$ and AA concentrations. The obtained result suggests that $\mathrm{Q}$ and AA can bind to HSA, and the binding of the antioxidants to HSA quenches the intrinsic fluorescence of HSA. Furthermore, a significant red shift (about $13 \mathrm{~nm}$ ) is observed with increasing Q concentration, which suggests that the fluorophore of HSA is placed in a more hydrophilic environment after addition of quince extract [33].

In order to clarify the fluorescence quenching mechanism induced by $\mathrm{Q}$ and AA, the fluorescence quenching data were analyzed using the Stern-Volmer equation [34]:

$$
\frac{F_{0}}{F}=1+K_{q} \tau_{0}[Q]=1+K_{S V}[Q]
$$

where: $F_{0}$ and $F$ are fluorescence intensities of HSA before and after addition of quencher, respectively, $K_{q}$ is a bimolecular quenching constant, $\tau_{0}$ is the life time of the fluorophore in the absence of quencher (the fluorescence life time of a biopolymer is about $5 \times 10^{-9} \mathrm{~s}$ [21], $[Q]$ is concentration of the quencher, and $K_{S V}$ is the Stern-Volmer quenching constant $\left(K_{S V}=K_{q} \times \tau_{0}\right)$.

On the basis of Eq. 3, binding constants $\left(K_{S V}\right)$ for the ligand-protein complex were determined using the linear regressions of the plots of $F_{0} / F$ versus [Q]. The plots were linear in the following ranges of concentration for Q $(2.5-75 \mu \mathrm{g} / \mathrm{mL})$ and for AA $(5-100 \mu \mathrm{g} / \mathrm{mL})$, (Figure 3). The SternVolmer quenching constants are summarized in Table 3. The result shows that $K_{S V}$ is inversely correlated with temperature.

Quenching can be classified as either dynamic (collisional encounters) or static quenching (formation of a complex) by different mechanisms. Dynamic and static quenching can be distinguished by their differing dependence on temperature and viscosity, or preferably by lifetime measurements. Higher temperatures result in faster diffusion and hence increased dynamic quenching; in contrast, higher temperatures will typically result in the dissociation of weakly bound complexes, and decreased static quenching [35]. The results showed that the values of $K_{S V}$ and $K_{b}$ constants for Q and AA decreased with increasing temperature. Our study indicated that the probable quenching mechanism of AA-HSA and Q-HSA interaction was initiated by complex formation rather than by dynamic collision.

The apparent binding constant $\left(K_{b}\right)$ and number of binding sites (n) can be calculated using the following equation [35]:

$$
\log \left(\frac{F_{0}-F}{F}\right)=\log K_{b}+n \log [Q]
$$

The values of $\mathrm{n}$ and $K_{b}$ were obtained by plotting $\log \left[\left(F_{0^{-}} F\right) / F\right]$ versus $\log [Q]$. The results for $\mathrm{Q}$ and AA at four different temperatures are given in Table 3. As indicated in Table 3, with increasing temperatures $K_{b}$ decreases for binding of Q and AA to HSA. The number of binding sites $(n)$ is approximately unity, which indicates that there is just a single binding site in HSA for Q and AA.

In general, the binding constant $K_{b}$ reflects the power of ligand-protein association and thus can be used for comparison of binding affinities of structurally-related ligands to a protein molecule connected with alterations in its secondary structure [30]. Usually, the drugs bind to high affinity sites with typical association constants in the range of $10^{4}-10^{6} \mathrm{M}^{-1}$ [36]. The value of $K_{b}$ for Q and AA, estimated on the basis of our study, is of the order of $10^{4}$, which indicates that there is probably strong interaction between HSA and the studied compounds. These results well correlate with our previously published data, that the Stern-Volmer constant for the chlorogenic acid - human serum albumin association is $3.0 \times 10^{4} \mathrm{M}^{-1}$. In addition, the calculated values of the bimolecular quenching rate constant $\left(K_{Q}\right)$ is $6.04 \times 10^{12} \mathrm{M}^{-1} \mathrm{~s}$ indicates at the static mechanism of quenching [18]. 
Table 3. Stern-Volmer quenching constants $\left(K_{S V}\right)$, binding constants $\left(K_{b}\right)$ and the numbers of the binding sites $(n)$ for the interaction of Cydonia oblonga Mill. extract and L(+) ascorbic acid with HSA at four different temperatures.

\begin{tabular}{lcccc}
\hline System & $\begin{array}{c}\text { Temperature } \\
{[\mathbf{K}]}\end{array}$ & $\begin{array}{c}\mathbf{K}_{\mathbf{s v}} \\
{[\mathbf{m L} / \mathbf{g}]}\end{array}$ & $\begin{array}{c}\mathbf{K}_{\mathbf{b}} \\
{[\mathbf{m L} / \mathbf{g}]}\end{array}$ & $\mathbf{n}$ \\
\hline Quince-HSA & & & & \\
& 295 & $29.7 \times 10^{3}$ & $47.5 \times 10^{3}$ & 0.83 \\
& 300 & $25.1 \times 10^{3}$ & $46.4 \times 10^{3}$ & 0.86 \\
& 305 & $23.9 \times 10^{3}$ & $40.1 \times 10^{3}$ & 0.87 \\
L(+)Ascorbic acid-HSA & 310 & $19.1 \times 10^{3}$ & $37.0 \times 10^{3}$ & 0.90 \\
& 295 & $49.9 \times 10^{3}$ & $27.3 \times 10^{3}$ & 1.19 \\
& 300 & $41.4 \times 10^{3}$ & $20.6 \times 10^{3}$ & 1.11 \\
& 305 & $37.0 \times 10^{3}$ & $16.2 \times 10^{3}$ & 1.16 \\
& 310 & $29.9 \times 10^{3}$ & $14.3 \times 10^{3}$ & 1.17 \\
\hline
\end{tabular}

Standard deviations (mean value of three independent experiments) were lower than $10 \%$
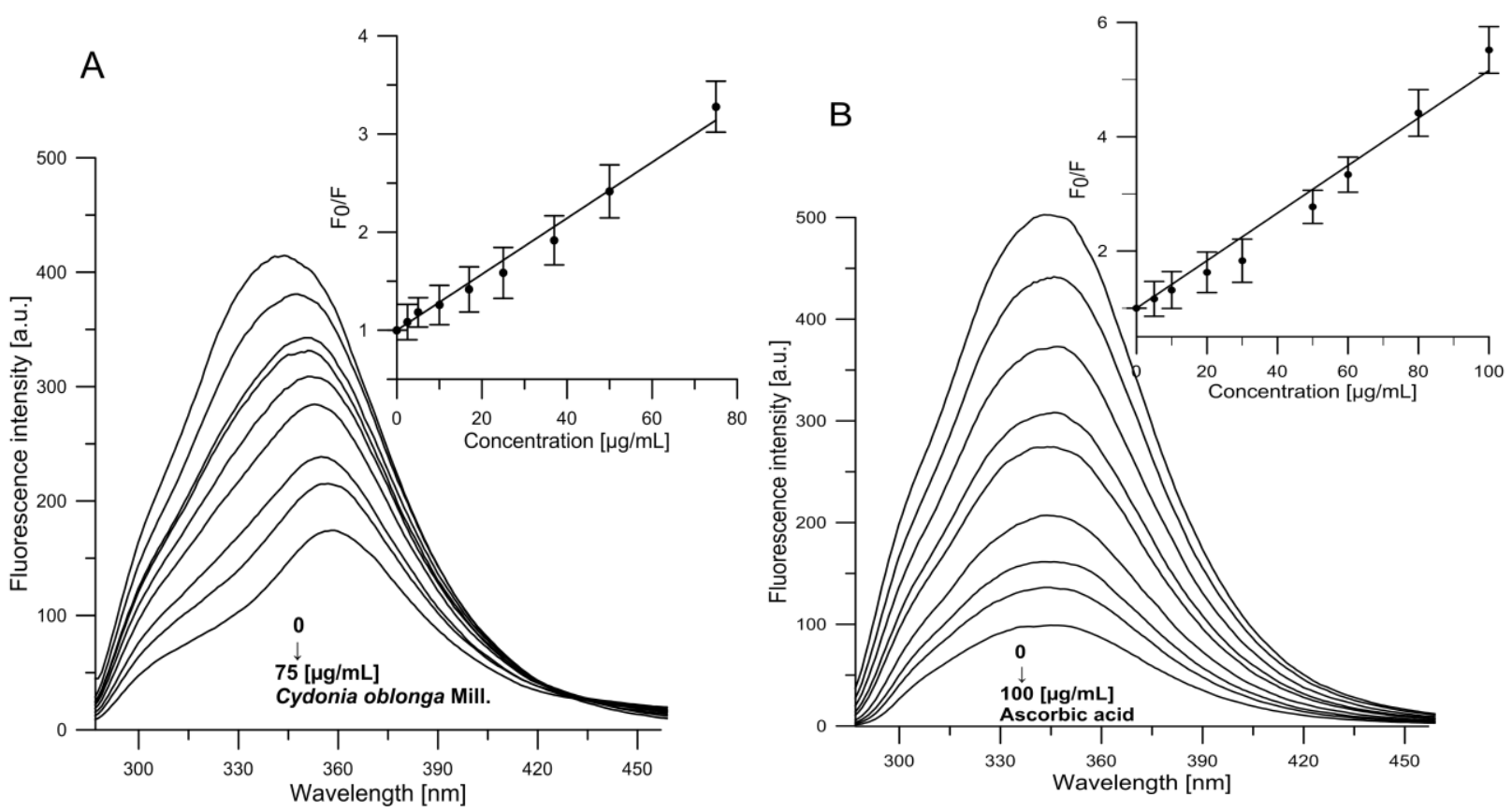

Figure 3. Emission spectra of HSA in the presence of various concentrations of Q (A) and AA (B), and Stern-Volmer plots of Fo/F against concentration for $\mathrm{Q}$ and AA $\left(\mathrm{HSA}=1.5 \cdot 10^{-5} \mathrm{M}, \lambda_{\mathrm{ex}}=280 \mathrm{~nm}, \mathrm{~T}=295 \mathrm{~K}\right)$.

\subsection{Cyclooxygenase Inhibition}

Our studies on the potential anti-inflammatory efficacy of quince extract have shown that the extract is able to inhibit the activity of the enzymes COX-1 and COX-2. Published reports confirm the anti-inflammatory activity of Cydonia oblonga Miller, e.g., in Essafi-Benkhadir et al. [37] it is shown that aqueous acetone extracts from the quince Cydonia oblonga Miller inhibited high levels of the proinflammatory cytokine TNF-a and the chemokine IL-8, used in LPS-stimulated human THP-1-derived macrophages. Quince extract has been compared to the non-steroidal anti-inflammatory drug (NSAIDs) indomethacin (Table 2). Our research showed that the drug cause inhibition of inflammatory enzymes at a concentration much lower than the extract. However, these drugs are highly toxic, and their use is frequently associated with side effects, ranging from dyspeptic symptoms to life-threatening bleeding or perforation of gastroduodenal ulcers [38]. The therapeutic anti- 
inflammatory action of NSAIDs is produced by the inhibition of COX-2, while the undesired side effects arise from inhibition of COX-1 activity [39]. Therefore search is under way for antiinflammatory drugs that selectively inhibit COX-2 rather than COX-1, so as not to affect the homeostasis functions of the prostanoids preferentially synthesised by COX-1 (and in particular to reduce the gastro-intestinal bleeding caused by COX-1 inhibition). Results of our studies have shown that quince extract's activity is 2 times higher for COX-2 than COX-1, the selectivity ratio COX2/COX- $1\left(\mathrm{IC}_{50}\right)$ for Q being 0.53 .

\section{Conclusion}

Results of the present study have shown that quince extract has a high biological activity, such as anti-inflammatory and antioxidant that can effectively protect the phosphatidylcholine liposome membrane and erythrocyte membrane against oxidation. The protection depends on the way the $\mathrm{Q}$ extract molecules interact with the membranes. Quince the extract constituents are is able to reside in the membrane, most likely in the portion that is close to the head groups of lipids. They can inhibit the propagation of lipid oxidation by intercepting intramembrane free radicals not only in redox reaction and also by hindering their diffusion by decreasing in the fluidity of the membrane hydrophilic and hydrophobic regions. Quince extract inhibits activity of enzymes participating in inflammatory reactions, exhibiting almost 2-times greater affinity to $\mathrm{COX}-2$ than $\mathrm{COX}-1$. What is more, Q extract can bind to the main plasma protein - human serum albumin - and quench the fluorescence of HSA. The quenching mechanism is of static type and due to the formation of a ground state complex. The ability of quince extract to interact with biological membranes and binding to human serum albumin are important factors of their pharmacological activity.

\section{Acknowledgements}

This work was supported by the agreement for development of young scientists, no. B030/0105/15 and funds for statutory activities of the Department of Physics and Biophysics of Wroclaw University of Environmental and Life Sciences.

\section{Conflict of Interest}

The authors declare no conflict of interest.

\section{Supporting Information}

Supporting Information accompanies this paper on http://www.acgpubs.org/RNP

\section{ORCID}

Paulina Strugała: 0000-0001-5949-4736

Sylwia Cyboran-Mikołajczyk: 0000-0001-8191-0804

Dorota Wyspiańska: 0000-0003-2045-3931

Anna Sokół-Łętowska: 0000-0003-2785-2791

Narcyz Piórecki: 0000-0002-0256-5510

Janina Gabrielska: 0000-0001-6125-0773

\section{References}

[1] A. Cencic and W. Chingwaru (2010). The role of functional foods, nutraceuticals and food supplements in intestinal health, Nutr. 2, 611-625.

[2] A. Pieroni, C. L. Quave, M. L. Villanelli, P. Mangino, G. Sabbatini, L. Santini, T. Boccetti, M. Profili, T. Ciccioli and L. G. Rampa (2004). Ethnopharmacognostic survey on the natural ingredients used in folk cosmetics, cosmeceuticals and remedies for healing skin diseases in the inland Marches, CentralEastern Italy, J. Ethnopharmacol. 91, 331-344.

[3] S. Kültür (2007). Medicinal plants used in Kırklareli province (Turkey), J. Ethnopharmacol. 111, 341364. 
[4] S. Pacifico, M. Gallicchio, A. Fiorentino, A. Fischer, U. Meyer and F. C. Stintzing (2012). Antioxidant properties and cytotoxic effects on human cancer cell lines of aqueous fermented and lipophilic quince (Cydonia oblonga Mill.) preparations, Food Chem. Toxicol. 50, 4130-4135.

[5] A. S. Magalhaes, B. M. Silva, J. A. Pereira, P. B. Andrade, P. Valentao and M. Carvalho (2009). Protective effect of quince (Cydonia oblonga Miller) fruit against oxidative hemolysis of human erythrocytes, Food Chem. Toxicol. 47, 1372-1377.

[6] M. Aslan, N. Orhan, D. D. Orhan and F. Ergun (2010). Hypoglycemic activity and antioxidant potential of some medicinal plants traditionally used in Turkey for diabetes, J. Ethnopharmacol. 128, 384-389.

[7] F. G. Silva and G. L. Oliveira (2013). Popular knowledge and antimicrobial activity of Cydonia oblonga Mill. (Rosaceae), Rev. Bras. de Plantas Med. 15, 98-103.

[8] M. Carvalho, B. M. Silva, R. Silva, P. Valentão, P. B. Andrade and M. L. Bastos (2010). First report on Cydonia oblonga Miller anticancer potential: Differential antiproliferative effect against human kidney and colon cancer cells, J. Agr. Food Chem. 58, 3366-3370.

[9] C. Grundemann, M. Papagiannopolous, M. Lamy, M. Mersch-Sundermann and R. Huber (2011). Immunomodulatory properties of a lemon-quince preparation (Gencydo) as an indicator of antiallergic properties, Phytomedicine 18, 760-768.

[10] R. Huber, F. G. Stintzing, D. Briemle, C. Beckmann, U. Meyer and C. Grundemann (2012). In vitro antiallergic effects of aqueous fermented preparations from Citrus and Cydonia fruits, Planta Med. 78, 334-340.

[11] A. Umar, G. Iskandar, A. Aikemu, W. Yiming, W. Zhou, B. Berké, B. Begaud and N. Moore (2015). Effects of Cydonia oblonga Miller leaf and fruit flavonoids on blood lipids and antioxidant potential in hyperlipidemia rats, J. Ethnopharmacol. 169, 239-243.

[12] A. Wojdyło, J. Oszmiański and P. Bielicki (2013). Polyphenolic composition, antioxidant activity, and polyphenol oxidase (PPO) activity of quince (Cydonia oblonga Miller) varieties, J. Agr. Food Chem. 61, 2762-2772.

[13] P. Strugała and J. Gabrielska (2014). Biological activity and stability in vitro of polyphenolic extracts as potential dietary supplements, Adv. Hyg. Exp. Med. 68, 1028-1035.

[14] J. T. Dodge, C. Mitchell and D. J. Hanahan (1963). The preparation and chemical characteristics of hemoglobin-free ghosts of erythrocytes, Arch. Biochem. Biophys. 100, 119-130.

[15] M. M. Bradford (1976). Rapid and sensitive method for the quantization of microgram quantities of protein utilizing the principle of protein-dye binding, Anal. Biochem. 72, 248-254.

[16] A. Z. Kucharska, A. Szumny, A. Sokół-Łętowska, N. Piórecki and S. V. Klymenko (2015). Iridoids and anthocyanins in cornelian cherry (Cornus mas L.) cultivars, J. Food Comp. Anal. 40, 95-102.

[17] A. Sokół-Łętowska, A. Z. Kucharska, K. Wińska, A. Szumny, A. Nawirska-Olszańska, P. Mizgier, and D. Wyspiańska (2014). Composition and antioxidant activity of red fruit liqueurs, Food Chem. 157, 533-539.

[18] P. Strugała, S. Cyboran-Mikołajczyk, A. Dudra, P. Mizgier, A. Z. Kucharska, T. Olejniczak and J. Gabrielska (2016a). Biological activity of Japanese quince extract and its interactions with lipids, erythrocyte membrane, and human albumin, J. Mem. Biol. 249, 393-410.

[19] S. Cyboran, P. Strugała, A. Włoch, J. Oszmiański and H. Kleszczyńska (2015). Concentrated green tea supplement: Biological activity and molecular mechanisms, Life Sci. 126, 1-9.

[20] A. Arora and G. M. Strasburg (1997). Development and validation of fluorescence spectroscopic assay to evaluate antioxidant efficiency. Application to metal chelators, J. American Oil. Chem. Soc. 74, $1031-1040$.

[21] L. Trnková, I. Boušová, V. Staňková and J. Dršata (2011). Study on the interaction of catechins with human serum albumin using spectroscopic and electrophoretic techniques, J. Mol. Structure. 985, 243250 .

[22] M. S. Jang and J. M. Pezzuto (1997). Assessment of cyclooxygenase inhibitors using in vitro assay systems, Method Cell Sci. 19, 25-31.

[23] P. Strugała, W. Gładkowski, A. Z. Kucharska, A. Sokół-Łętowska and J. Gabrielska (2016b). Antioxidant activity and anti-inflammatory effect of fruit extracts from blackcurrant, chokeberry, hawthorn, and rosehip, and their mixture with linseed oil on a model lipid membrane, Eur. J. Lipid Sci. Tech. 118, 461-474.

[24] B. M. Silva, P. B. Andrade, F. Ferreres, A. L. Domingues, R. M. Seabra and A. Ferreira (2002). Phenolic profile of quince fruit (Cydonia oblonga Miller) (pulp and peel), J. Agr. Food Chem. 50, 4615-4618.

[25] J. Kolniak-Ostek, A. Z. Kucharska, A. Sokół-Łętowska and I. Fecka (2016). Characterization of phenolic compounds of thorny and thornless blackberries, J. Agr. Food Chem. 63, 3012-3021. 
[26] P. Mizgier, A. Z. Kucharska, A. Sokół-Łętowska, J. Kolniak-Ostek, M. Kidoń and I. Fecka (2016). Characterization of phenolic compounds and antioxidant and anti-inflammatory properties of red cabbage and purple carrot extracts, J. Funct. Foods. 21, 133-146.

[27] D. Wyspiańska, A. Z. Kucharska, A. Sokół-Łętowska and J. Kolniak-Ostek (2016). Physico-chemical, antioxidant, and anti-inflammatory properties and stability of hawthorn (Crataegus monogyna Jacq.) procyanidins microcapsules with inulin and maltodextrin, J. Sci. Food Agric. 97(2), 669-678.

[28] C. A. Rice-Evans, N. J. Miller and G. Paganga (1996). Structure-antioxidant activity relationships of flavonoids and phenolic acids, Free Rad. Biol. Med. 20, 933-956.

[29] S. A. Sanchez, M. A. Tricerri, G. Gunther and E. Gratton (2007). Modern Research and Educational Topics in Microscopy, ed: A. Mendez-Vilas and J. Díaz, Formatex, Badajoz, pp. 1007-1014.

[30] P. Tammela, L. Laitinen, A. Galkin, T. Wennberg, R. Heczko, H. Vuorela, J. P. Slotte and P. Vuorela (2004). Permeability characteristics and membrane affinity of flavonoids and alkyl gallates in Caco-2 cells and in phospholipid vesicles, Arch. Biochem. Biophys. 425, 193-199.

[31] I. Bernhardt and J. C. Ellory (2003). Red cell membrane transport in health and disease. Springer, Berlin, New York.

[32] M. Suwalsky and M. Avello (2014). Antioxidant capacity of Ugni molinae fruit extract on human erythrocytes: an in vitro study, J. Mem. Biol. 247, 703-712.

[33] X. Li, D. Chen, G. Wang and Y. Lu (2013). Study of interaction between human serum albumin and three antioxidants: Ascorbic acid, $\alpha$-tocopherol, and proanthocyanidins, Eur. J. Med. Chem. 70, 22-36.

[34] J. R. Lakowicz (2006). Principles of Fluorescence Spectroscopy. Plenum Press, New York.

[35] H. Gao, L. Lei, J. Liu, Q. Kong, X. Chena and Z. Hua (2004). The study on the interaction between human serum albumin and a new reagent with antitumour activity by spectrophotometric methods, $J$. Photochem. Photobiol A: Chem. 167, 213-221.

[36] L. Trynda-Lemiesz and K. Wiglusz (2011). Effects of glycation on meloxicam binding to human serum albumin, J. Mol. Structure 995, 35-40.

[37] K. Essafi-Benkhadir, A. Refai, I. Riahi, S. Fattouch, H. Karoui and M. Essafi (2012). Quince (Cydonia oblonga Miller) peel polyphenols modulate LPS-induced inflammation in human THP-1-derived macrophages through NF-jB, p38MAPK and Akt inhibition, Biochem. Biophys. Res. Commun. 418, 180-185.

[38] T. D. Warner, F. Giuliano, I. Vojnovic, A. Bukasa, J. A. Mitchel and J. R. Vane (1999). Nonsteroid drug selectivities for cyclooxygenase-1 rather than cyclooxygenase-2 are associated with human gastrointestinal toxicity: a full in vitro analysis, Proc. Nat. Ac. Sc. USA, 96, 7563-7568.

[39] A. Zarghi and S. Arfaei (2011). Selective COX-2 Inhibitors: A review of their structure-activity relationships, Iranian J. Pharm. Res. 10, 655-683.

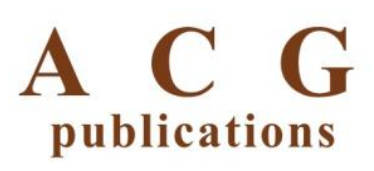

(C) 2017 ACG Publications 